5-1-2014

\title{
On the Exponentiated Weibull Distribution for Modeling Wind Speed in South Western Nigeria
}

Olanrewaju I. Shittu

University of Ibadan, Nigeria, oi.shittu@ui.edu.ng

KA. Adepoju

University of Ibadan, Nigeria

Follow this and additional works at: http://digitalcommons.wayne.edu/jmasm

Part of the Applied Statistics Commons, Social and Behavioral Sciences Commons, and the Statistical Theory Commons

\section{Recommended Citation}

Shittu, Olanrewaju I. and Adepoju, KA. (2014) "On the Exponentiated Weibull Distribution for Modeling Wind Speed in South Western Nigeria," Journal of Modern Applied Statistical Methods: Vol. 13 : Iss. 1 , Article 28.

DOI: $10.22237 /$ jmasm/1398918420

Available at: http://digitalcommons.wayne.edu/jmasm/vol13/iss1/28

This Regular Article is brought to you for free and open access by the Open Access Journals at DigitalCommons@WayneState. It has been accepted for inclusion in Journal of Modern Applied Statistical Methods by an authorized editor of DigitalCommons@WayneState. 


\section{On the Exponentiated Weibull Distribution for Modeling Wind Speed in South Western Nigeria}

\author{
Olanrewaju I. Shittu \\ University of Ibadan \\ Ibadan, Nigeria
}

\author{
K. A. Adepoju \\ University of Ibadan \\ Ibadan, Nigeria
}

One of the bases for assessment of wind energy potential for a specified region is the probability distribution of wind speed. Thus, appropriate and adequate specification of the probability distribution of wind speed becomes increasingly important. Several distributions have been proposed for describing wind distribution. Among the most popular distributions is the Weibull whose choice is due to its flexibility. An exponentiated Weibull distribution is proposed as an alternative to model wind speed data with a view to comparing it with the existing Weibull distribution. Results indicate that the proposed distribution outperforms the existing Weibull distribution for modeling wind speed data in terms of minimum Akaike information criterion (AIC) and likelihood function. Thus, the exponentiated Weibull can be used as an alternative distribution that adequately describe the wind speed and thereby provide better representation of the potentials of wind energy.

Keywords: Wind power, Weibull, exponentiated Weibull, model selection criteria, maximum likelihood estimation

\section{Introduction}

Energy demand increases proportionally as world population grows rapidly. Governments and societies become interested to renewable energies. Wind energy is considered the most attractive as it ensures high output power compared to other renewable energies. Nevertheless, the assessment of the wind energy potential is complicated since the wind speed availability is probabilistic. Several statistical distributions have been used for the description of the wind speed distribution. The two-parameter Weibull distribution function has been commonly

Dr. Shittu and Mr. Adepoju are lecturers in the Department of Statistics. Email Dr. Shittuatoi.shittu@ui.edu.ng. 


\section{ON THE EXPONENTIATED WEIBULL DISTRIBUTION}

used in many fields including wind energy assessment (Rehman et al., 1994; Bivona et al., 2003).

Silva and Cordeiro (2012) were among the first among researchers to use compound distributions to model wind speed. They showed that Burr type XII distribution outperformed the commonly used Weibull distribution. Therefore, this article received its motivation from this and attempts to model wind speed using exponentiated Weibull distribution, which is a generalization of the Weibull distribution for increased and improved modeling potential.

\section{Weibull Distribution}

The Weibull distribution is characterized by two parameters $K$ and $S$, the shape and scale respectively. A random variable $V$ (wind speed) is distributed as Weibull if it satisfies the following probability density function.

$$
f_{(V)}=\frac{K}{C}\left(\frac{V}{C}\right)^{K-1} \exp \left[-\left(\frac{V}{C}\right)^{K}\right]
$$

The corresponding distribution function is

$$
F_{(V)}=1-\exp \left[-\left(\frac{V}{C}\right)^{K}\right]
$$

If $V$ denotes the wind speed, then the average wind speed is expressed as

$$
E_{(V)}=\int_{0}^{\infty} V f(V) d v=\int_{0}^{\infty} V \frac{K}{C}\left(\frac{V}{C}\right)^{K-1} \exp \left[-\left(\frac{V}{C}\right)^{K}\right] d v
$$

giving rise to

$$
E_{(V)}=\bar{V}=C \Gamma\left(1+\frac{1}{K}\right)
$$

The variance of $V$ is

$$
\operatorname{Var}(V)=\int_{0}^{\infty}(V-\bar{V})^{2} f(v) d v
$$


which on simplification gives

$$
\sigma^{2}=\operatorname{Var}(V)=C^{2}\left[\Gamma\left(1+\frac{2}{K}\right)-\Gamma^{2}\left(1+\frac{1}{K}\right)\right]
$$

from which

$$
\sigma=C\left[\Gamma\left(1+\frac{2}{K}\right)-\Gamma^{2}\left(1+\frac{1}{K}\right)\right]^{\frac{1}{2}} .
$$

\section{Method of Estimating the Weibull Parameters}

Commonly used methods known as graphical and maximum likelihood methods are now considered.

\section{Graphical Method}

From (2)

$$
\frac{1}{1-F_{(V)}}=\exp \left[\left(\frac{V}{C}\right)^{K}\right]
$$

Introducing $I n$ to both sides results in

$$
\operatorname{In}\left\lfloor\frac{1}{1-F_{(V)}}\right\rfloor=\left(\frac{V}{C}\right)^{K}
$$

and further introduction of $I n$ results in

$$
\operatorname{In} \operatorname{In}\left\lfloor\frac{1}{1-F_{(V)}}\right\rfloor=K|n V-K| n C
$$

Equation (10) can be expressed as $Y=a X+b$ where 


\section{ON THE EXPONENTIATED WEIBULL DISTRIBUTION}

$$
Y=\operatorname{In} \operatorname{In}\left\lfloor\frac{1}{1-F_{(V)}}\right\rfloor, X=\operatorname{Inv}, a=K \text { and } b=-K \operatorname{In} C
$$

\section{Maximum Likelihood Method}

Harter and Moore (1965) were the earliest statisticians to use the maximum likelihood procedure because of its desirable characteristics. Given a random sample of size $n$ wind speed drawn from a probability density function in (1), then the likelihood function will be

$$
L\left(V_{1}, V_{2}, \ldots . V_{n}, K, C\right)=\prod_{i=1}^{n}\left(\frac{K}{C}\right)\left(\frac{V_{i}}{C}\right)^{k-1} \exp \left[-\left(\frac{V_{i}}{C}\right)^{K}\right]
$$

The logarithm of (11) becomes

$$
l=n \log \frac{K}{C}+(K-1) \sum_{i=1}^{n} \log \left(\frac{V}{C}\right)-\sum_{i=1}^{n}\left(\frac{V_{i}}{C}\right)^{K}
$$

by differentiating (12) with respect to $K$ and $C$ in turn and equating to zero, the following are obtained

$$
\begin{gathered}
\frac{\delta l}{\delta C} \Rightarrow \frac{-n K}{C}+\frac{K}{C} \sum_{i=1}^{n}\left(\frac{V_{i}}{C}\right)^{K}=0 \\
\frac{\delta l}{\delta K}=\frac{n}{K}+\sum_{i=1}^{n} \log \left(\frac{V_{i}}{C}\right)^{K}-\log \left(\frac{V_{i}}{C}\right)=0
\end{gathered}
$$

Equations (13) and (14) are termed normal equations and can be solved numerically to obtain the maximum likelihood estimates of $K$ and $C$.

\section{Exponentiated Weibull Distributions}

According to Mudhokar, et al., (1995), the exponentiated Weibull density function is defined as 


$$
g(V)=\frac{K \delta}{C}\left[1-\exp \left(-\frac{V}{C}\right)^{K}\right]^{\delta-1}\left(\frac{V}{C}\right)^{K-1} \exp \left(-\frac{V}{C}\right)^{K}
$$

where $K, C$ and $d>0 \quad V_{i}>0$.

This distribution is proposed to model wind speed for the first time. For adequate determination of wind speed, the parameters in equation (15) need to be estimated. For this, we adopt the use of maximum likelihood method.

As before if $V_{1}, V_{2}, \ldots ; V_{n}$ is a random sample of size $n$ wind speed drawn from the density function in (15), then the likelihood function is

$$
L\left(V_{1}, V_{2}, \ldots, V_{n}, K, C, \delta\right)=\frac{K^{n} \delta^{n}}{C^{n}} \prod_{i=1}^{n}\left[1-\exp \left(-\frac{V}{C}\right)^{K}\right]^{\delta-1} \prod_{i=1}^{n}\left(\frac{V_{i}}{C}\right)^{K-1} \exp \left(-\frac{V_{i}}{C}\right)^{K}
$$

The corresponding log-likelihood function is obtained by finding the logarithm of (16) is

$$
\begin{aligned}
l & =n \log K+n \log \delta-n \log C \\
& +(\delta-1) \sum_{i=1}^{n} \log \left(1-\exp \left(\frac{V_{i}}{C}\right)^{K}\right)+(K-1) \sum_{i=1}^{n} \log \left(\frac{V_{i}}{C}\right)-\sum_{i=1}^{n} \log \left(\frac{V_{i}}{C}\right)^{K} .
\end{aligned}
$$

Taking the derivative of (17) with respect to $K, C$ and $\delta$, results in

$$
\begin{aligned}
\frac{\delta l}{\delta K} & =\frac{n}{K}+(\delta-1) \sum_{i=1}^{n}\left\lfloor\frac{\left(\frac{V_{i}}{C}\right)^{K} \exp \left(-\frac{V_{i}}{C}\right)^{K} \log \left(\frac{V_{i}}{C}\right)}{\left(1-\exp \left(-\frac{V_{i}}{C}\right)^{K}\right)}\right\rfloor \\
& +\sum_{i=1}^{n} \log \left(\frac{V_{i}}{C}\right)^{K}-\log \left(\frac{V_{i}}{C}\right)=0
\end{aligned}
$$




$$
\begin{gathered}
\frac{\delta l}{\delta C}=\frac{-n}{C}+\frac{K(\delta-1)}{C} \sum_{i=1}^{n}\left\lfloor\frac{\left(\frac{V_{i}}{C}\right)^{K} \exp \left(-\frac{V_{i}}{C}\right)^{K}}{\left(1-\exp \left(-\frac{V_{i}}{C}\right)^{K}\right)}\right\rfloor-\frac{n(K-1)}{C}-\frac{K}{C} \sum_{i=1}^{n}\left(\frac{V_{i}}{C}\right)^{K} \\
\frac{\delta l}{\delta d}=\frac{n}{d}+\sum_{i=1}^{n} \log \left(1-\exp \left(-\frac{V_{i}}{C}\right)^{K}\right) .
\end{gathered}
$$

Equations (18), (19) and (20) are solved iteratively to obtain the maximum likelihood estimates of the parameters $K, C$ and $d$.

\section{Moments of the Exponentiated Weibull Distribution}

Following the density function in (15), its $r^{\text {th }}$ moment can be obtained as:

$$
\begin{aligned}
& \mu_{r}^{\prime}=E\left(X^{r}\right)=\int_{0}^{\infty} \frac{K d}{C} V^{r}\left(1-\exp \left(\frac{-V_{i}}{C}\right)^{K}\right)^{d-1}\left(\frac{V_{i}}{C}\right)^{K-1} \exp \left(\frac{-V_{i}}{C}\right)^{K} d y \\
& \text { If } y=\left(\frac{V_{i}}{C}\right)^{K} \Rightarrow V=y^{\frac{1}{K} C} \text { and } d v=\frac{C^{K}}{K V^{K-1}} d y,
\end{aligned}
$$

which reduces to

$$
\mu_{r}^{\prime}=E\left(X^{r}\right)=\int\left(y^{1 / K^{C}}\right)^{r} \exp (-y)(1-\exp (-y))^{d-1} d y
$$

Note from binomial series expansion that

$$
(1-m)^{b}=\sum_{j=0}^{\infty}(-1)^{j}\left(\begin{array}{l}
b \\
j
\end{array}\right) m^{j}, \text { then }(1-\exp (-y))^{d-1}=\sum_{j=0}^{\infty}(-1)^{j}\left(\begin{array}{c}
d-1 \\
j
\end{array}\right) \exp \left(-y_{j}\right)
$$

thus, equation (21) becomes 


\section{SHITTU \& ADEPOJU}

$$
\mu_{r}^{\prime}=C^{r} d \sum_{j=0}^{\infty}(-1)^{j}\left(\begin{array}{c}
d-1 \\
j
\end{array}\right) \int_{0}^{\infty} y^{r / K} \exp (-y(1+j)) d y
$$

If $P=y(1+j) \Rightarrow y=\frac{P}{1+j}$ and $d y=\frac{d P}{1+j}$, then

$$
\mu_{r}^{\prime}=E\left(X^{r}\right)=C^{r} d \sum_{j=0}^{\infty} \frac{(-1)^{j}\left(\begin{array}{c}
d-1 \\
j
\end{array}\right)}{(1+j)^{r / K+1}} \int_{0}^{\infty} P^{r / K} \exp (-P) d y,
$$

therefore, the $r^{\text {th }}$ moment of the exponentiated Weibull distribution is

$$
E\left(X^{r}\right)=C^{r} d \sum_{j=0}^{\infty} \frac{(-1)^{j}\left(\begin{array}{c}
d-1 \\
j
\end{array}\right)}{(1+j)^{r / K+1}} \Gamma\left(\frac{r}{K}+1\right) .
$$

For simplicity let $w_{j}=\frac{(-1)^{j}\left(\begin{array}{r}d-1 \\ j\end{array}\right)}{(1+j)^{r / K+1}}$

$$
E\left(X^{r}\right)=C^{r} d \sum_{j=0}^{\infty} w_{j} \Gamma\left(\frac{r}{K}+1\right)
$$

If $r=1$ and $d=1 \Rightarrow \sum w_{j}=1$, then this reduces to the mean of the Weibull distribution and the moments, such as the Mean, Variance, Skewness and Kurtosis, can be obtained from (24).

The mean and variance are respectively

$$
E\left(V_{i}\right)=C d \Gamma\left(\frac{1}{K}+1\right) \sum_{j=0}^{\infty} \frac{(-1)^{j}\left(\begin{array}{c}
d-1 \\
j
\end{array}\right)}{(1+j)^{\frac{1}{K}+1}}
$$




\section{ON THE EXPONENTIATED WEIBULL DISTRIBUTION}

$\operatorname{Var}\left(V_{i}\right)=C^{2} d \Gamma\left(\frac{2}{K}+1\right) \sum_{j=0}^{\infty} \frac{(-1)^{j}\left(\begin{array}{c}d-1 \\ j\end{array}\right)}{(1+j)^{\frac{1}{K}+1}}-C^{2} d^{2} \Gamma^{2}\left(\frac{1}{K}+1\right)\left(\sum_{j=0}^{\infty} \frac{(-1)^{j}\left(\begin{array}{c}d-1 \\ j\end{array}\right)}{(1+j)^{\frac{1}{K}+1}}\right)^{2}$

\section{Application}

The fitting of monthly wind data collected across regions in the south western part of Nigeria was considered using data from the period between 1992 and 2012. Using the R-Package, the following results were obtained.

\section{Estimates and Goodness-of-Fit for the Wind Speed Data}

\begin{tabular}{cccccc} 
January & \multicolumn{5}{c}{ MLE } \\
Distributions & $\mathbf{K}$ & $\mathbf{C}$ & $\delta$ & $\mathbf{- 2 l o g ~ I ~}$ & AlC \\
\hline Weibull & 0.2276 & 0.0002 & 1 & 19.3754 & 23.3754 \\
$\begin{array}{c}\text { Exponentiated } \\
\text { Weibull }\end{array}$ & 0.6678 & 1 & 10.2721 & 0.9916 & 4.9916 \\
\hline
\end{tabular}

\section{February}

\begin{tabular}{cccccc} 
Distributions & $\mathbf{K}$ & $\mathbf{C}$ & $\delta$ & $\mathbf{- 2 \operatorname { l o g } \text { I }}$ & AIC \\
\hline Weibull & 0.2168 & 0.0001 & 1 & 21.32016 & 25.32016 \\
$\begin{array}{c}\text { Exponentiated } \\
\text { Weibull }\end{array}$ & 0.6598 & 1 & 13.5975 & 3.15927 & 7.15927 \\
\hline
\end{tabular}

\section{March}

\begin{tabular}{cccccc} 
Distributions & $\mathbf{K}$ & $\mathbf{C}$ & $\delta$ & $\mathbf{- 2 \operatorname { l o g } \text { I }}$ & AIC \\
\hline Weibull & 0.20399 & 0.00006 & 1 & 23.75956 & 27.75956 \\
$\begin{array}{c}\text { Exponentiated } \\
\text { Weibull }\end{array}$ & 0.641638 & 1 & 15.335852 & 6.31854 & 10.31854 \\
\hline
\end{tabular}




\section{SHITTU \& ADEPOJU}

\section{April}

\begin{tabular}{cccccc}
\multicolumn{5}{c}{ MLE } & \\
Distributions & $\mathbf{K}$ & $\mathbf{C}$ & $\delta$ & $\mathbf{- 2} \log$ I & AIC \\
\hline Weibull & 0.19996 & 0.00005 & 1 & 24.55724 & 28.55724 \\
$\begin{array}{c}\text { Exponentiated } \\
\text { Weibull }\end{array}$ & 0.6896499 & 1 & 41.4258026 & 15.38302 & 19.38302 \\
\hline
\end{tabular}

\section{May}

\begin{tabular}{cccccc} 
Distributions & $\mathbf{K}$ & $\mathbf{C}$ & $\delta$ & $\mathbf{- 2 \operatorname { l o g } \text { I }}$ & AIC \\
\hline $\begin{array}{c}\text { Weibull } \\
\begin{array}{c}\text { Exponentiated } \\
\text { Weibull }\end{array}\end{array}$ & 0.209261 & 0.000072 & 1 & 22.73786 & 26.73786 \\
\hline
\end{tabular}

\section{June}

\begin{tabular}{cccccc} 
Distributions & $\mathbf{K}$ & $\mathbf{C}$ & $\delta$ & $\mathbf{- 2 \operatorname { l o g } \text { I }}$ & AIC \\
\hline Weibull & 0.2096060 & 0.000073 & 1 & 22.67258 & 26.67258 \\
$\begin{array}{c}\text { Exponentiated } \\
\text { Weibull }\end{array}$ & 0.6915926 & 1 & 25.247869 & 10.20779 & 14.20779 \\
\hline
\end{tabular}

\section{July}

\begin{tabular}{cccccc} 
Distributions & $\mathbf{K}$ & $\mathbf{C}$ & $\delta$ & $\mathbf{- 2 \operatorname { l o g } \text { I }}$ & AIC \\
\hline Weibull & 0.21815 & 0.000106 & 1 & 21.0735 & 25.0735 \\
$\begin{array}{c}\text { Exponentiated } \\
\text { Weibull }\end{array}$ & 0.677590 & 1 & 15.3195704 & 5.094789 & 9.094789 \\
\hline
\end{tabular}

\section{August}

\begin{tabular}{cccccc}
\multicolumn{5}{c}{ MLE } \\
Distributions & $\mathbf{K}$ & $\mathbf{C}$ & $\delta$ & $\mathbf{- 2 \operatorname { l o g } \text { I }}$ & AIC \\
\hline Weibull & 0.211048 & 0.0000782 & 1 & 22.39852 & 26.39852 \\
$\begin{array}{c}\text { Exponentiated } \\
\text { Weibull }\end{array}$ & 0.692516 & 1 & 23.699390 & 9.502349 & 13.502349 \\
\hline
\end{tabular}




\section{ON THE EXPONENTIATED WEIBULL DISTRIBUTION}

\section{September}

\begin{tabular}{cccccc}
\multicolumn{5}{c}{ MLE } \\
Distributions & $\mathbf{K}$ & $\mathbf{C}$ & $\delta$ & $\mathbf{- 2 \operatorname { l o g } \text { I }}$ & AIC \\
\hline $\begin{array}{c}\text { Weibull } \\
\begin{array}{c}\text { Exponentiated } \\
\text { Weibull }\end{array}\end{array}$ & 0.2077786 & 0.00067 & 1 & 23.0227 & 27.0227 \\
\hline
\end{tabular}

\section{October}

\begin{tabular}{cccccc} 
Distributions & $\mathbf{K}$ & $\mathbf{C}$ & $\delta$ & $\mathbf{- 2 \operatorname { l o g } \text { I }}$ & AIC \\
\hline Weibull & 0.222508 & 0.000127 & 1 & 20.28256 & 24.28256 \\
$\begin{array}{c}\text { Exponentiated } \\
\text { Weibull }\end{array}$ & 0.6600494 & 1 & 11.9804517 & 2.943342 & 6.943342 \\
\hline
\end{tabular}

\section{November}

\begin{tabular}{cccccc}
\multicolumn{5}{c}{ MLE } \\
Distributions & $\mathbf{K}$ & $\mathbf{C}$ & $\delta$ & $\mathbf{- 2 \operatorname { l o g } \text { I }}$ & AIC \\
\hline $\begin{array}{c}\text { Weibull } \\
\begin{array}{c}\text { Exponentiated } \\
\text { Weibull }\end{array}\end{array}$ & 0.2262799 & 0.0001477 & 1 & 19.61016 & 23.61016 \\
\hline
\end{tabular}

\section{December}

\begin{tabular}{cccccc}
\multicolumn{5}{c}{ MLE } \\
Distributions & $\mathbf{K}$ & $\mathbf{C}$ & $\delta$ & $\mathbf{- 2 \operatorname { l o g } \text { I }}$ & AIC \\
\hline Weibull & 0.2426764 & 0.0002682 & 1 & 16.81126 & 20.81126 \\
$\begin{array}{c}\text { Exponentiated } \\
\text { Weibull }\end{array}$ & 0.6716818 & 1 & 7.055548 & 5.285842 & 9.285842 \\
\hline
\end{tabular}

\section{Summary Statistics}

\begin{tabular}{cccccc} 
Min & $\mathbf{1}^{\text {st }}$ Quarter & Median & Mean & 3rd $^{\text {rd }}$ Quarter & Mae \\
\hline 1.54 & 2.94 & 4.06 & 4.578 & 5.88 & 9.81 \\
\hline
\end{tabular}

Note: Kurtosis $=2.502187$, Skewness $=0.6333066$

\section{Conclusion}

The performance of Exponentiated Weibull and Weibull distribution functions to model wind energy was systematically compared. It was observed that the log 
likelihood values and the Akaike information criterion (AIC) for the Exponentiated Weibull was always smaller for the Weibull distribution for each month except the month of November. This indicates that the proposed Exponentiated Weibull distribution outperformed the existing Weibull distribution for wind speed data in terms of minimum AIC and likelihood function over the months of the years under review. Thus, the exponentiated Weibull can be used as an alternative distribution that adequately describes wind speed, and may provide better representation of the potentials of wind energy.

\section{References}

Akpinar, S. \& Akpinar, E. K. (2009). Estimation of wind energy potential using finite mixture distribution models. Energy Conversion and Management, 50(4): 877-84.

Bivona, S., Burlon, R., \& Leone, C.. (2003). Hourly wind speed analysis in Sicily. Renewable Energy, 28(9): 1371-1385.

Burton, T., Sharpe, D., Jenkins, N., \& Bossanyi, E. (2001). Wind energy handbook. Wiley.

Carta, J. A., Ramirez, P., \& Velazquez, S. (2009). A review of wind speed probability distributions used in wind energy analysis Case studies in the Canary Islands. Renewable and Sustainable Energy Reviews, 13(5): 933-55.

Carta, J. A., Ramirez, P., \& Velazquez, S. (2008) Influence of the level of fit of a density probability function to wind-speed data on the WECS means power output estimation. Energy Conversion and Management, 49(10):2647-55.

Carta, J. A. \& Ramirez, P. (2007). Analysis of two-component mixture Weibull statistics for estimation of wind speed distributions. Renewable Energy, 32(3): 518-31.

Carta, J. A. \& Ramirez, P. (2007). Use of finite mixture distribution models in the analysis of wind energy in the Canarian Archipelago. Energy Conversion and Management, 48(1): 281-91.

Celik, A. N. (2004). A statistical analysis of wind power density based on the Weibull and Rayleigh models at the southern region of Turkey. Renewable Energy, 29(4): 593-604.

Chang, T-J \& Tu, Y-L. (2007). Evaluation of monthly capacity factor of WECS using Chronological and probabilistic wind speed data: a case study of Taiwan. Renewable Energy, 32(12): 1999-2010. 


\section{ON THE EXPONENTIATED WEIBULL DISTRIBUTION}

Garcia, A., Torres, J. L., Prieto, E., \& Francisco, A. D. (1998). Fitting wind speed distributions: a case study. Solar Energy, 62(2): 139-44.

Harris, R. I. (2006). Errors in gev analysis of wind epoch maxima from Weibull parents. Wind and Structures, An International Journal, 9(3): 179-91.

Harris, R. I. (2005). Generalized Pareto methods for wind extremes. Useful tool or mathematical mirage? Journal of Wind Engineering and Industrial Aerodynamics, 93(5): 341-60. doi:10.1016/j.jweia.2005.02.004.

Harter, H. L. \& Moore, A. H. (1965). Maximum-Likelihood Estimation of the Parameters of Gamma and Weibull Populatlons from Complete and from Censored Samples. Technometrics, 7: 639 - 643.

Hennessey, J. P. (1977). Some aspects of wind power statistics. Journal of Applied Meteorology and Climatology, 16(2): 119-28.

International Electrotechnical Commission. Wind turbines - part 1: design requirements. Tech. rep. 61400-1, (Ed.3). International Electrotechnical Commission; 2005.

Jaramillo, O. A. \& Borja, M. A. (2004). Wind speed analysis in La Ventosa, Mexico: a bimodal probability distribution case. Renewable Energy, 29(10): $1613-30$.

Kiss, P. \& Janosi, I. M. (2008). Comprehensive empirical analysis of ERA40 surface wind speed distribution over Europe. Energy Conversion and Management, 49(8): 2142-51. doi:10.1016/j.enconman.2008.02.003.

Krishnamurthy, K. (2006). Handbook of statistical distributions with applications. New York: Chapman \& Hall.

Lackner, M. A., Rogers, A. L., \& Maxwell, J. F. (2008). Uncertainty Analysis in MCP-Based Wind Resource Assessment and Energy Production Estimation. Journal of solar energy engineering, 130(3): 31006.

Maxwell, J. F., McGowan, J. G., Rogers, A. L. (2002). Wind energy explained: theory, design and application. New York: Wiley.

Mudholkar, G. S., Srivastava, D. K. \& Friemer, M. (1995). The exponentiated Weibull family: A reanalysis of the bus-motor-failure data. Technometrics, 37: 436-445.

NOAA's National Data Buoy Center. (2009) National Data Buoy Center. Retrieved July $1^{\text {st }}, 2009$, from http://www.ndbc.noaa.gov/.

Ramirez, P. \& Carta, J. A. (2005). Influence of the data sampling interval in the estimation of the parameters of the Weibull wind speed probability density 


\section{SHITTU \& ADEPOJU}

distribution: a case study. Energy Conversion and Management, 46(15-16):

2419-38.

Rehman, S., Halawani, T. O., Husain, T. (1994). Weibull parameters for wind speed distribution in Saudi Arabia. Solar Energy, 53(6): 473-479.

Silva, B. R. and Cordeiro, G. M. (2012). The Burr XII power series distribution: a new compounding family. In press. Brazilian Journal of Probability and Statistics. http://imstat.org/bjps/papers/BJPS234.pdf

Simiu, E., Heckert, N., Filliben, J., \& Johnson, S. (2001). Extreme wind load estimates based on the Gumbel distribution of dynamic pressures: an assessment. Structural Safety, 23(3): 221-9.

Wind powering America. (2009). US Dept. of Energy. Retrieved September, 2009, from http:// www.windpoweringamerica.gov 


\section{ON THE EXPONENTIATED WEIBULL DISTRIBUTION}

\section{Appendix}

\section{QQ Plots}
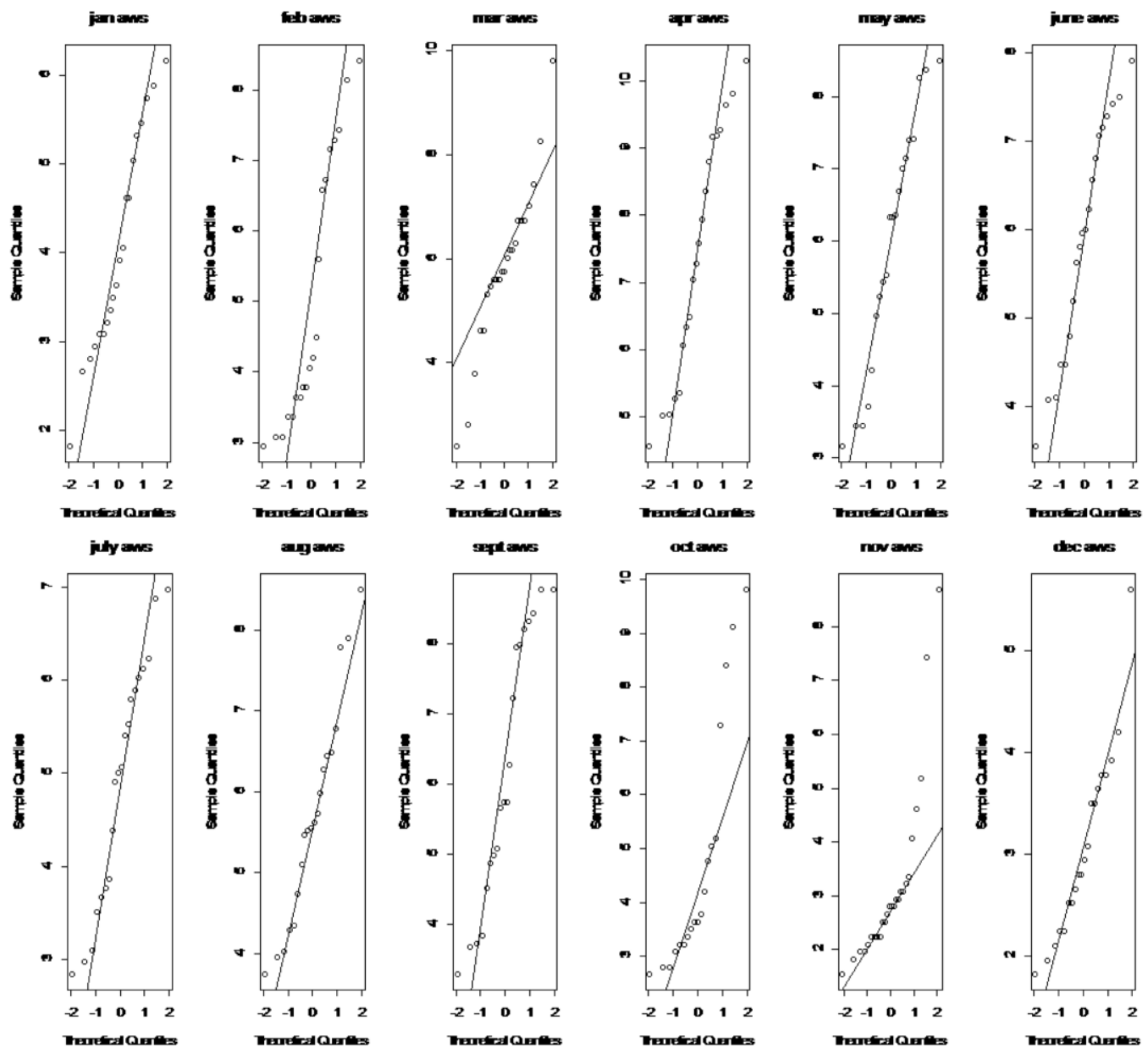


\section{Histograms}
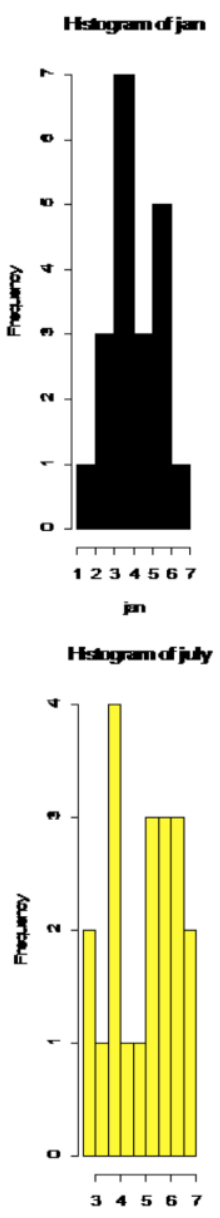

iny
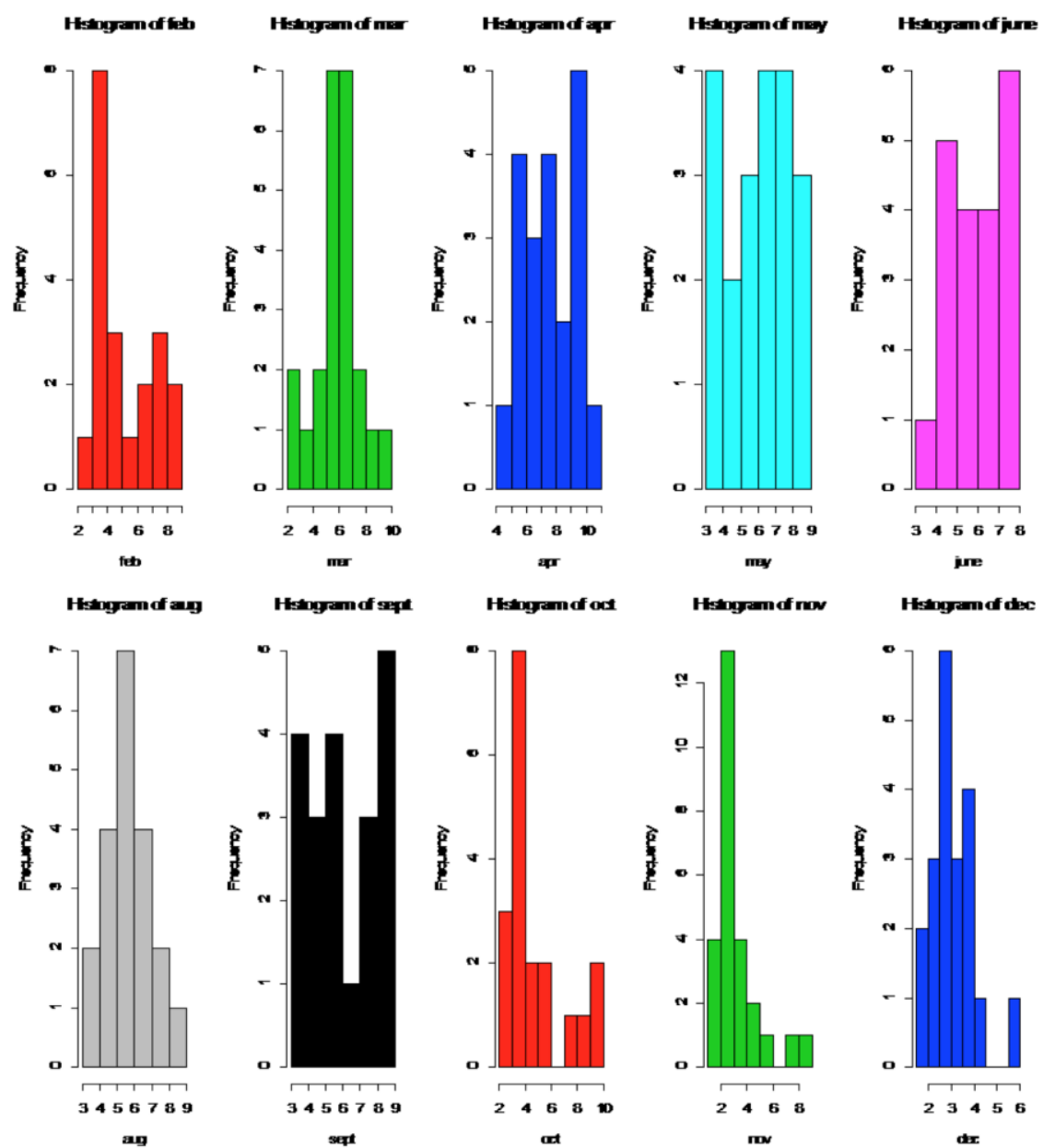

ine

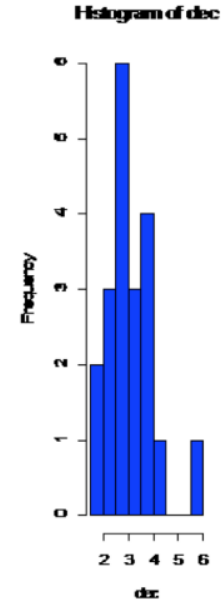

